\title{
Determinants of Postnatal Care Services among Mothers in Nakasongola Health Centre IV, Nakasongola District.
}

\author{
Eunice Vivian Asingoa,1, Jane Frances Namukasaa \\ ${ }^{a}$ Faculty of Health Sciences, Uganda Martyrs University
}

\begin{abstract}
\end{abstract}

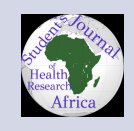

\section{Background: ${ }^{a}$}

Poor utilization of postnatal services remains a serious maternal and child health challenge. Post Natal Services are defined as those services provided to both mothers and their infants immediately after birth up to 6 weeks of age. The postnatal period is a critical phase in the lives of mothers and new-born babies as most maternal and infant deaths occur during this time. In May, June, and July 2019, Nakasongola Health Centre IV, had 622 deliveries. However, there were only 229 postnatal attendances in the same period. A study was carried out to identify the determinants of postnatal care services utilization among mothers in Nakasongola Health Centre IV, Nakasongola District.

\section{Methodology:}

The study design was descriptive cross-sectional and it employed both quantitative and qualitative data collection methods. A sample size of 60 respondents was selected using the purposive sampling procedure. An interview guide was used to collect data.

\section{Results:}

$30(50 \%)$ sometimes received support from their husbands to access postnatal care, 16 (26.7\%) lack of awareness as a socio-economic factor, $14(23.3 \%)$ poverty. $40(67 \%)$ reported that cultural beliefs did not allow postnatal mothers to freely move and access health care services, $60(100 \%)$ used herbs to treat the ailment in the postnatal period for various reasons. Half 30 (50\%) resided 2 - $3 \mathrm{~km}$ away from Nakasongola Health Center IV and although 40 (67\%) had ever used post-natal services at Nakasongola Health Center IV, 14 (35\%) waited for 2 - 3 hours before receiving services yet all 60 (100\%) agreed that long waiting time influenced service utilization.

Conclusion and recommendations:

Respondents faced various socio-economic, cultural, and health facility determinants of postnatal care services utilization among mothers. Sensitization about the availability of postnatal services and the importance of using these services, participation, and involvement of male partners among others.

\footnotetext{
${ }^{a}$ email: asingoeunice@gmail.com submitted: 03th/06/2021accepted: 08th/06/2021
}

\section{Background of the Study}

Poor utilization of postnatal services remains a serious maternal and child health challenge (Nikiema et al., 2014). Post Natal Services are defined as those services provided to both mothers and their infants immediately after birth up to 6 weeks of age, World Health Organization (WHO, 2018). The postnatal period is a critical phase in the lives of mothers and newborn babies as most maternal and infant deaths occur during this time (WHO, 2013).

Globally, ensuring the use of postnatal services remains a challenge to safe motherhood as many women continue to delay to report for delivery, giving rise to many serious complications for both 
the mothers and their children as well as increased maternal mortality (Keusch et al., 2011).

In Sub Saharan Africa, poor utilization of postnatal services among postnatal mothers is a rampant problem and this had greatly influenced high infant and maternal mortality rates in this period in many countries in sub-Saharan Africa and this remains one of the key factors why many subSaharan African countries failed to achieve goal number 5 of the Millennium Development Goals, to reduce infant and maternal mortality (Achola et al., 2013). For instance, in Ghana, Adamu et al., (2015) observed that only $45 \%$ of postnatal mothers attended and utilized postnatal services, implying that the biggest number of mothers missed out on the chance to be assessed and had their children assessed as recommended, thus exposing them to various risks and complications.

Conversely, in East Africa, late reporting for delivery remained prevalent, despite better attendance of other maternal services such as Antenatal Care [ANC] and skilled delivery services (Kasenga et al., 2013). The report further highlighted that despite efforts made by the Ministry of Health $[\mathrm{MoH}]$ to provide maternity services reachable to mothers, only $42 \%$ of postnatal mothers attended and utilized postnatal services, while poor utilization was especially great among rural-based mothers. This was attributed to various factors including unavailability of reliable and affordable means of transport, long distance to health facilities, and cultural factors among other factors.

Similarly, in Uganda, utilization of postnatal services remains a problem for maternal and infant health, especially in rural areas. Despite initiatives put by $\mathrm{MOH}$ on safe motherhood programs to improve access and utilization of the services such as the Delivery of Improved Services for Health (DISH), the use of postnatal services remains low. Kagaayi et al., (2014), found out that only $44 \%$ of mothers adequately attended and utilized postnatal services as recommended by WHO. This was attributed to factors such as the attitude of mothers, cultural norms, beliefs and practices, poverty, lack of support, long distances to facilities among many other factors.

The ideal situation is that postnatal mothers and their babies should attend postnatal services at 6 days, 6 weeks, and 6 months as recommended by $\mathrm{WHO}$ as this helps to identify, isolate and treat any potential complications which may occur to mothers and their babies during this period.

Nakasongola District is one of the districts in Uganda where so many programs of safe motherhood have been initiated to promote maternal and infant health. However, reports from Uganda Demographic and Health Survey (UDHS, 2016) showed that factors like social-economic, social-cultural, and health facility were still major problems preventing many postnatal mothers from accessing and utilizing these lifesaving services.

Despite high ANC attendance as well skilled delivery by pregnant women in Nakasongola Health Centre IV, there were very low rates of utilization of postnatal services. According to Health Management Information System (HMIS, 2019) data for May, June, and July in Nakasongola Health Centre IV, there were 622 deliveries at the health center. However, there were only 229 postnatal attendances in the same period.

There was no study carried out to identify the determinants of postnatal care services utilization among mothers in Nakasongola Health Centre IV and it was also not clear whether the women were benefiting from the programs on safe motherhood.

\section{Methodology Study Design and Rationale}

The study design was descriptive cross-sectional, employing both quantitative and qualitative data collection methods. It was a cross-sectional type of design because it involved the collection of data at a single point in time and from a group of respondents whose characteristics such as age, parity, marital status, level of education, and occupation were described. The design was descriptive as it described the data as it was without any changes.

\section{Study Setting and Rationale}

The study was conducted in Nakasongola Health Centre IV, Nakasongola District which is located in Central Uganda. The health center offers many health care services including immunization, child health services, HIV/AIDS management services, general patient management, laboratory services, nutrition services, antenatal, maternity, and postnatal services, EMTCT program as well as VCT services among many others. The study area was selected because the problem under study had been noted on the ground by the researcher. It was also accessible since the researcher is a staff of the hospital. 


\section{Study Population}

The study included only post-natal mothers attending Young Child Clinic in Nakasongola Health Centre IV, Nakasongola District.

\section{Sample Size Determination}

The sample size was 60 respondents, postnatal mothers attending Young Child Clinic in Nakasongola Health Centre IV. This sample size was determined by the use of Morgan and Krejce's (1970) table for sample size determination. See appendix. Hence, according to the table, with a study population of 79 pregnant women attending the ANC clinic every clinic day, the sample size for the study was 59 respondents. However, the researcher rounded this up to 60 respondents and this was deemed representative enough of the entire study population.

\section{Sampling Procedure}

The researcher used a simple random sampling procedure to select the required number of postnatal mothers in Nakasongola Health Centre IV. In this procedure, the researcher wrote the words YES and NO on pieces of paper, placed them in an enclosed box, shook it then offered potential respondents an opportunity to participate by picking papers from the box. Any respondent who picked a paper with the word YES written on it was requested to participate in the study. This continued until the total number of respondents to be interviewed per day was achieved.

\section{Inclusion Criteria}

The study included only post-natal mothers attending Young Child Clinic in Nakasongola Health Centre IV who were available during the data collection period and were willing to voluntarily consent to participate in the study. The study excluded all post-natal mothers who were ill and could not participate as well as those who refused to voluntarily consent to participate in the study.

\section{Definition of Variables}

The independent variable for the study included:

Social-economic determinants of postnatal care services utilization among mothers

Cultural determinants of postnatal care services utilization among mothers

Health facility determinants of postnatal care services utilization among mothers

The dependent variables for the study included:

Utilization of postnatal care services

\section{Research Instruments}

Data was collected using an approved semistructured interview guide which consisted of both open and closed-ended questions. This tool was selected because the study involved mixed respondents who were literate and illiterate and could not understand English used to develop the questionnaire. The interview guide was pre-tested at Wabigalo Health Center III which assisted the researcher to assess the accuracy and reliability of the tool before using it for data collection. The tool was also translated into a language that the respondents understand.

\section{Data Collection Procedure}

Before approaching and collecting data from respondents at the MCH Clinic, the researcher was accompanied and introduced to the respondents by the In-Charge of the clinic and explained the purpose of the study. The researcher made a selfintroduction and then administered questionnaires to respondents at the $\mathrm{MCH}$ Clinic. This improved efficiency and confidentiality during data collection. The researcher interviewed 10 respondents per day for a total of 60 respondents in 6 days.

\section{Data Management}

Data management included data editing before leaving the area of study to ensure that there were no mistakes or areas left blank, and any found were corrected before leaving the area of study. The researcher stored the collected data under lock and key and it was only accessible to the researcher.

\section{Data Analysis}

Data were analyzed by the use of SPSS version 25 which assisted in coming up with frequencies and percentages as units of measurements. Findings were presented in form of tables, pie charts, and graphs.

\section{Ethical Considerations}

A letter of introduction was obtained from Uganda Martyrs University, introducing the researcher to the administration of Nakasongola Health Center IV and seeking permission to carry out the study. Participants were assured of maximum confidentiality of all information given and numbers instead of names were used to identify the respondents. Respondents were advised that participation was voluntary and that withdraw from the study at any given time would not affect them in any way. The study only commenced after its objec- 
tives had been well explained to participants, and they had understood and voluntarily consented to participate in the study.

\section{Limitation of the Study}

The researcher encountered financial constraints in collecting data from the internet and libraries and printing and transport costs. The researcher overcame this limitation by drawing up a budget that was strictly followed to utilize the available means.

The researcher also encountered difficulty in getting the required information from the respondents as some feared to open up to give the needed information. The researcher overcame these limitations by promising and ensuring maximum confidentiality of the identities of the respondents as well as the information is given.

The researcher encountered delays in interviewing the respondents as they did not report to the facility at the same time. However, the researcher planned adequate time and was also patient with the respondents to enable quality data collection.

\section{Dissemination of Results}

The results were forwarded to Uganda Martyrs University for the award of a Bachelors Degree in Midwifery Science, a copy given to the administration of Nakasongola Health Center IV for actions as per the recommendations while the researcher also retained a copy for future reference.

\section{Results}

\section{Description of the sample}

Demographic and Social Characteristics

The interview guide included some key demographic and social characteristics such as age, level of education, occupation, marital status, and several children. The demographic information was assessed to find out its relationship with the determinants of postnatal care services utilization among mothers in Nakasongola Health Centre IV, Nakasongola District. The results are presented as follows.

\section{1}

\subsubsection{Figure 1: Distribution of respondents by age $(n=60)$.}

Results showed that 24 (40\%) respondents were in the age range of $26-35$ years, followed by 20
(33.3\%) who were in the age range of $18-25$ years while the least 16 (26.7\%) were 36 years and above.

\subsubsection{Figure 2: Distribution of respondents by level of education $(n=60)$.}

Results showed that 24 (40\%) respondents never went to school, followed by 16 (27\%) who attained primary level education, $12(20 \%)$ attained secondary level education while the least $8(13 \%)$ attained tertiary level education.

\subsubsection{Figure 3: Distribution of respondents by occupation $(n=60)$} Findings showed that $36(60 \%)$ respondents were peasant/farmers, followed by 14 (23\%) who were self-employed while the least 10 (17\%) were civil servants.

\subsubsection{Figure 4: Distribution of respondents by marital status$$
(n=60)
$$

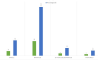

Results showed that 38 (63.3\%) respondents were married, followed by $12(20 \%)$ who were single, $6(10 \%)$ were divorced/separated while the least 4 (6.7\%) were widowed.

\subsubsection{Table 1: Distribution of respondents by number of children $n=60$}

Half 30 (50\%) of the respondents had $2-3$ children, followed by $20(33.3 \%)$ respondents who had 5 children and above while the least $10(16.7 \%)$ had 1 child.

\subsection{Research Question One: Socioeconomic determinants of postnatal care services utilization} among mothers

\author{
6.2.1 Figure 5: Distribution of \\ respondents by monthly \\ household income $(n=60)$
}

Findings showed that 24 (40\%) respondents had a monthly household income of 50,000 - 100,000shs, followed by $16(26.7 \%)$ who had a monthly household income of 100,000 - 200,000shs, 12 (20\%) had a monthly income of 300,000 shs and more while the least 8 (13.3\%) had $0-50,000$ shs. 


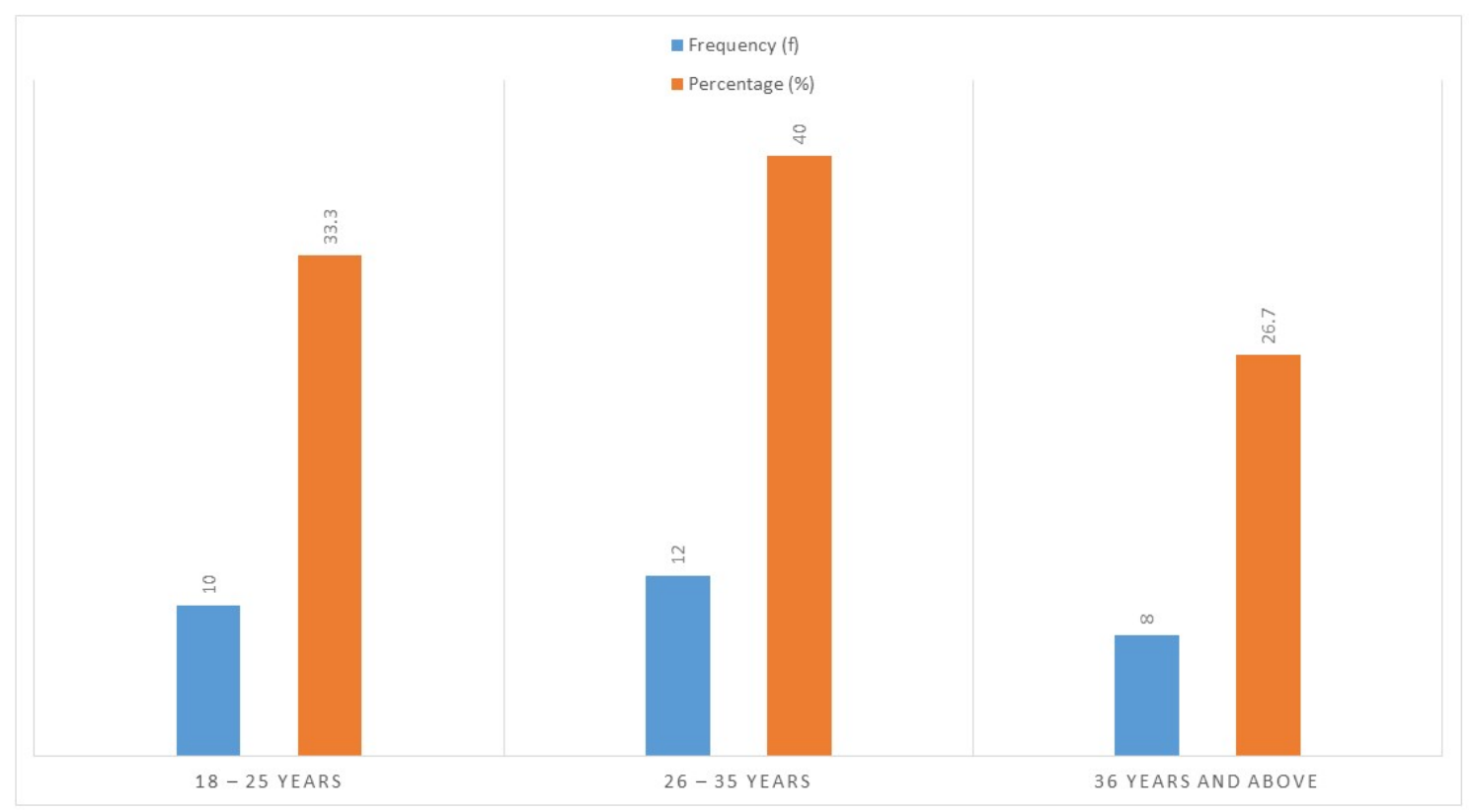

Chart 1. Distribution of respondentsby age

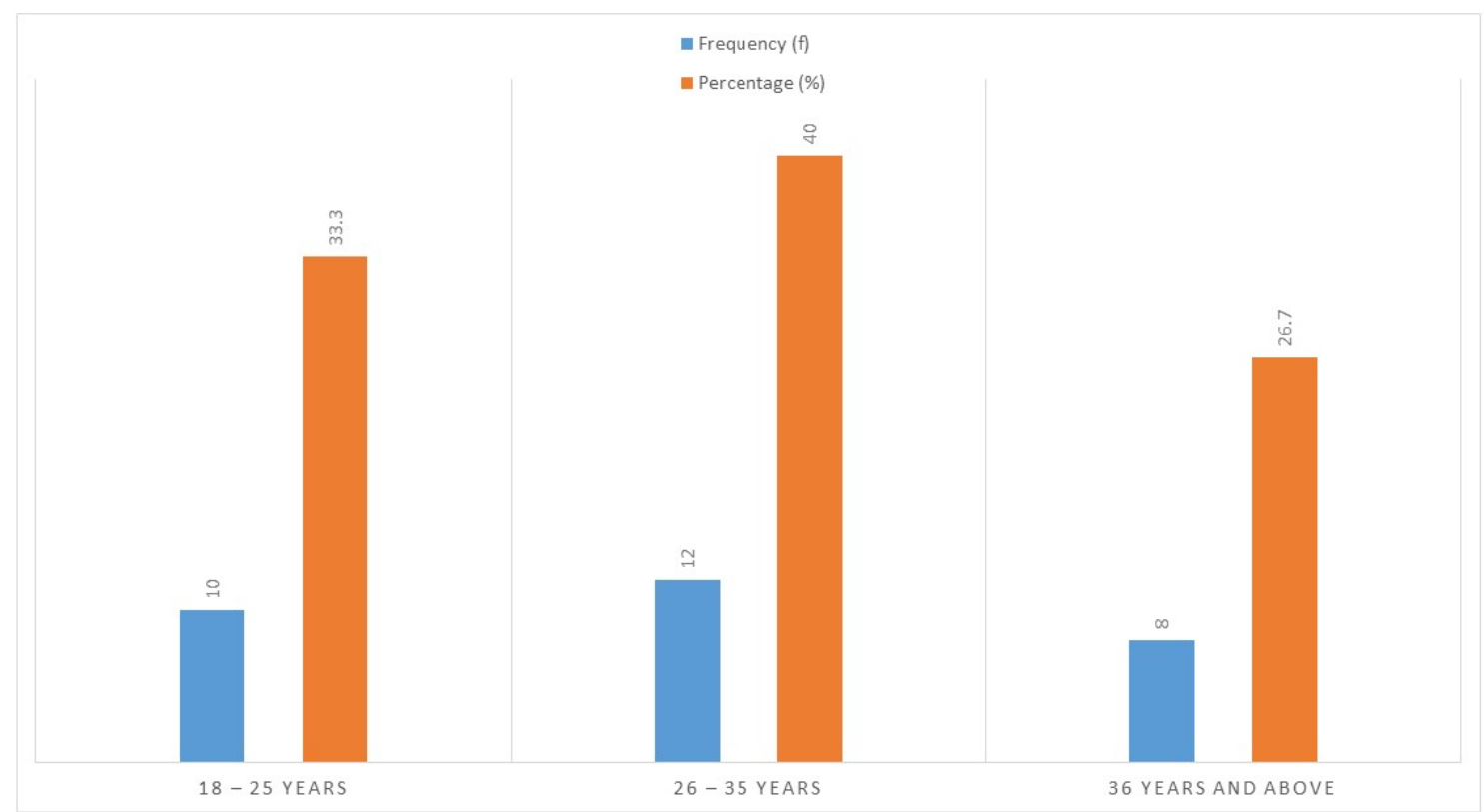

Chart 2. Distribution of respondentsby level of education

Table 1. Distribution of respondents by number of children

\begin{tabular}{lll}
\hline Responses & Frequency & Percentage (\%) \\
1 child & 10 & 16.7 \\
2 - 3 children & 30 & 50 \\
4 children and above & 20 & 33.3 \\
Total & $\mathbf{6 0}$ & $\mathbf{1 0 0}$ \\
\hline
\end{tabular}




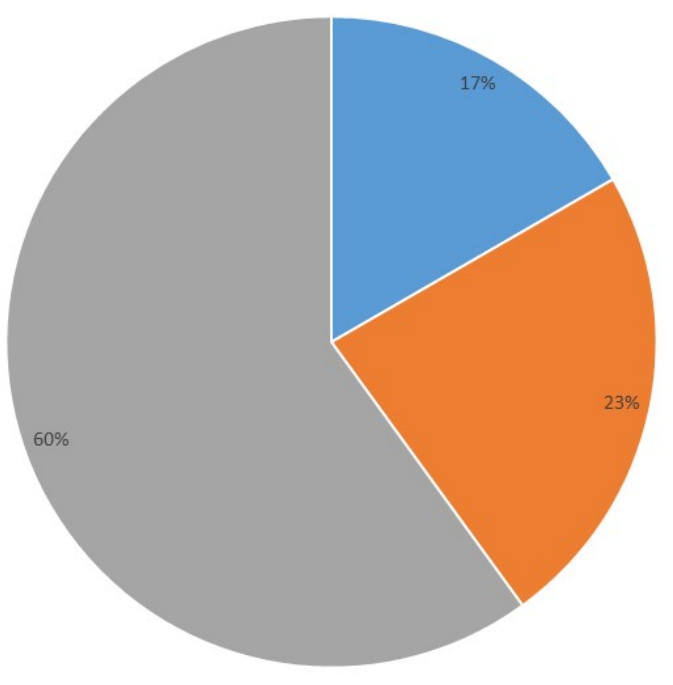

- Civil servant

- Self employed

Chart 3. Distribution of respondentsby occupation

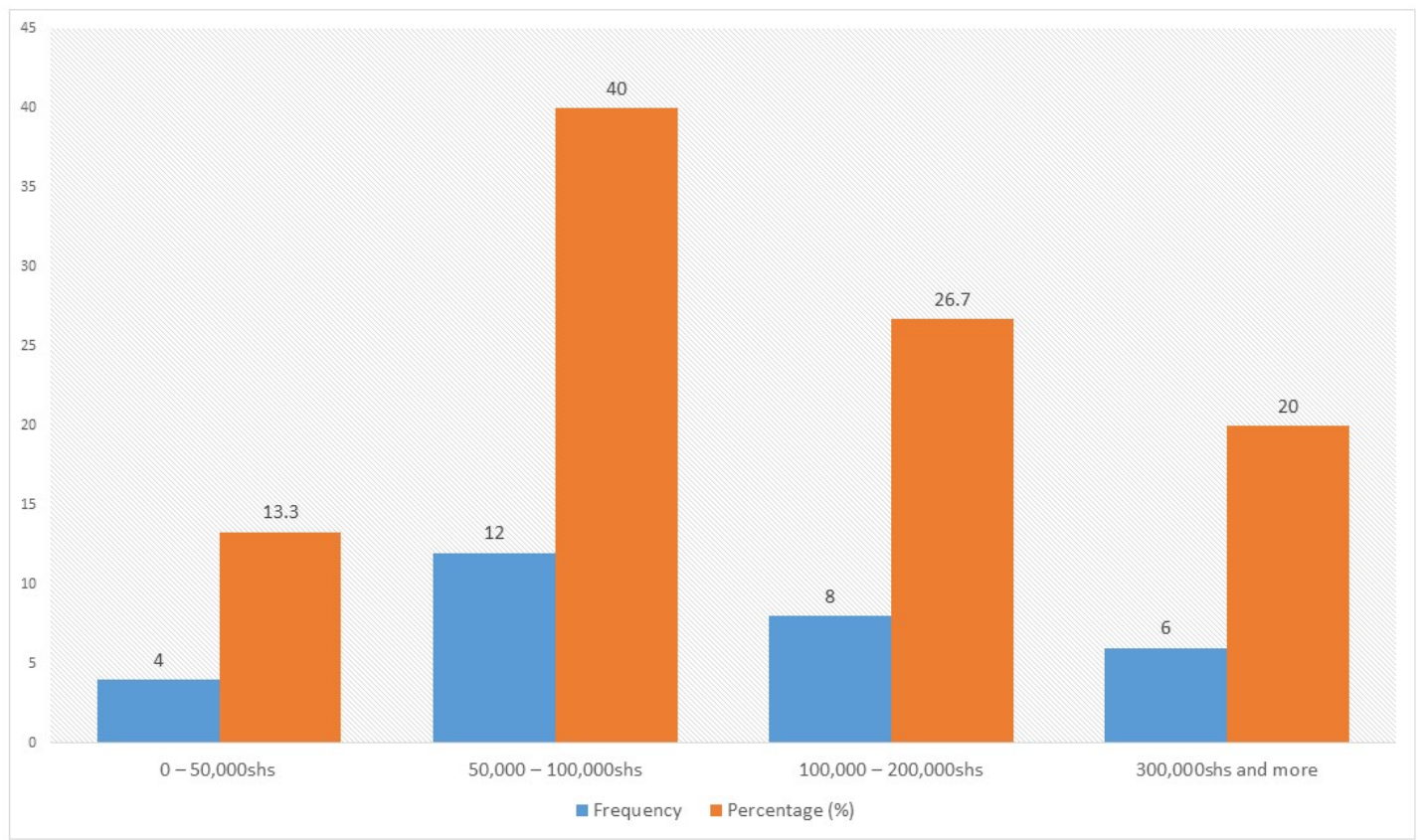

Chart 4. Distribution of respondentsby monthly household income 


\subsubsection{Table 2: Whether respondents received support from their husband to access postnatal care $n=60$}

Half 30 (50\%) respondents reported that they sometimes received support from their husbands to access post-natal care, followed by 20 (33.3\%) who never received support from their husbands while the least $10(16.7 \%)$ always received support from their husbands.

\subsubsection{Figure 6: Kind of support respondents received from their partners $(n=40)$}

Out of the 40 respondents who received support from their partners to ensure attendance of postnatal care, half $20(50 \%)$ reported that they received financial support, followed by 12 (30\%) who reported emotional support while the least 8 (20\%) reported receiving material support.

\subsubsection{Table 3: Other socio economic factors influencing utilization of postnatal care $n=60$}

Results showed that 16 (26.7\%) respondents mentioned lack of awareness as a socio economic determinant of postnatal care services utilization among mothers, followed by 14 (23.3\%) who reported poverty, 12 (20\%) reported unemployment, $8(13.3 \%)$ reported lack of funds for transport, 6 $(10 \%)$ reported lack of funds for health services while the least 4 (6.7\%) reported lack of support.

\subsection{Research Question Two: Cultural determinants of post-natal care services utilization among mothers}

Figure 7: Whether cultural beliefs, are post-natal mothers allowed to freely move and access health care services $(n=60)$

Results showed most $40(67 \%)$ respondents reported that cultural beliefs did not allow post-natal mothers to freely move and access health care services while the least 20 (33\%) reported that their culture allowed them to move freely.

Figure 8: Whether cultural beliefs limiting postnatal mothers' movements influenced utilization of postnatal care services $(n=40)$

Out of the 40 respondents who reported that cultural beliefs did not allow postnatal mothers to freely move and access health care services, most 24 (60\%) reported that these cultural beliefs limited mothers' utilization of postnatal services while the least $16(40 \%)$ reported that it did not.

\subsubsection{Table 4: Whether women used herbs to treat ailments in the postnatal period $n=60$}

All 60 (100\%) respondents reported using herbs to treat ailment in the postnatal period.

\subsubsection{Figure 9: Reasons why women used herbs to treat ailments $(n=60)$} Results showed that 24 (40\%) respondents reported that they used herbs to treat ailments because of cultural beliefs and practices, followed by $16(26.7 \%)$ who reported cost effectiveness of the herbs, $12(20 \%)$ ready availability of the herbs while the least $8(13.3 \%)$ reported efficacy of the herbs for treating ailments.

\subsection{Research Question Three: Health facility determinants of postnatal care services utilization among mothers}

\subsubsection{Table 5: Distance to Nakasongola Health Center IV from respondents' home $n=60$}

Half 30 (50\%) of the respondents resided $2-3 \mathrm{~km}$ away from Nakasongola Health Center IV, followed by $20(33.3 \%)$ who resided $2-3 \mathrm{~km}$ away while the least $10(16.7 \%)$ resided less than $1 \mathrm{~km}$ away.

Figure 10: Distribution of respondents who used postnatal care services at Nakasongola Health Center IV $(n=60)$

Results showed that $40(67 \%)$ respondents had ever used postnatal services at Nakasongola Health Center IV while the least 20 (33\%) had never used postnatal services at Nakasongola Health Center IV.

\subsubsection{Figure 11: Waiting time to be attended to $(n=40)$}

Out of the 40 respondents who had attended postnatal services before, most 14 (35\%) reported waiting for $2-3$ hours before receiving services, followed by 12 (30\%) who waited 30 minutes -1 hour, $8(20 \%)$ waited for more than 3 hours while the least $6(15 \%)$ waited for less than 30 minutes. 
Table 2. Whether respondents received support from their husband to access postnatal care.

\begin{tabular}{lll}
\hline Responses & Frequency & Percentage (\%) \\
Sometimes & 30 & 50 \\
Always & 10 & 16.7 \\
Never & 20 & 33.3 \\
Total & $\mathbf{6 0}$ & $\mathbf{1 0 0}$ \\
\hline
\end{tabular}

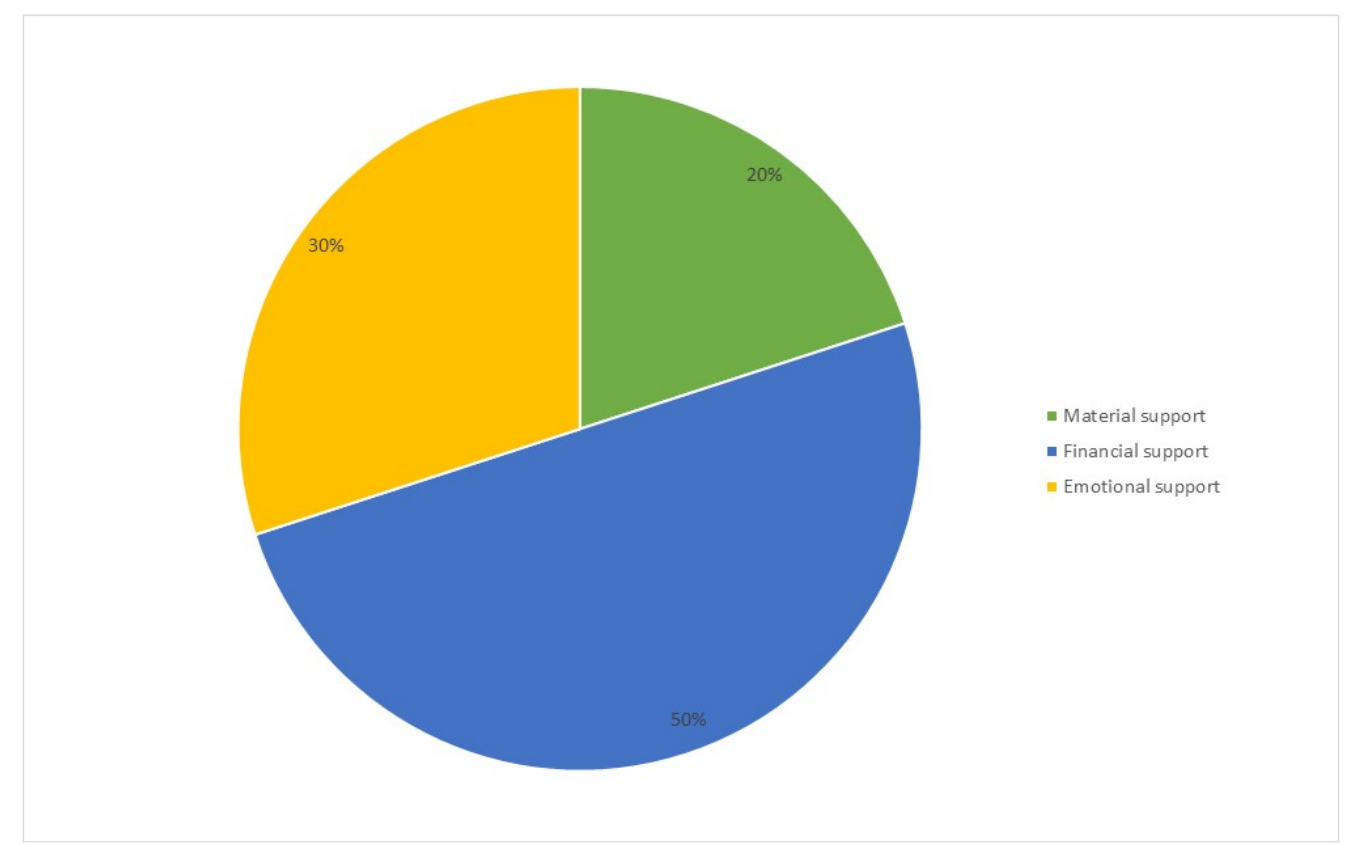

Chart 5. Kind of support respondents received from their partners

Table 3. Other socio economic factors influencing utilization of postnatal care

\begin{tabular}{lll}
\hline Responses & Frequency & Percentage (\%) \\
Lack of awareness & 16 & 26.7 \\
Poverty & 14 & 23.3 \\
Unemployment & 12 & 20 \\
Lack of funds for transport & 8 & 13.3 \\
Lack of funds for health services & 6 & 10 \\
Lack of support & 4 & 6.7 \\
Total & $\mathbf{6 0}$ & $\mathbf{1 0 0}$ \\
\hline
\end{tabular}

Table 4. Whether women used herbs to treat ailments in the postnatal period

\begin{tabular}{lll}
\hline Responses & Frequency & Percentage (\%) \\
Yes & 60 & 100 \\
No & 0 & 0 \\
Total & 60 & 100 \\
\hline
\end{tabular}


Chart 6. Whether cultural beliefs, are post-natal mothers allowed to freely move and access health care services

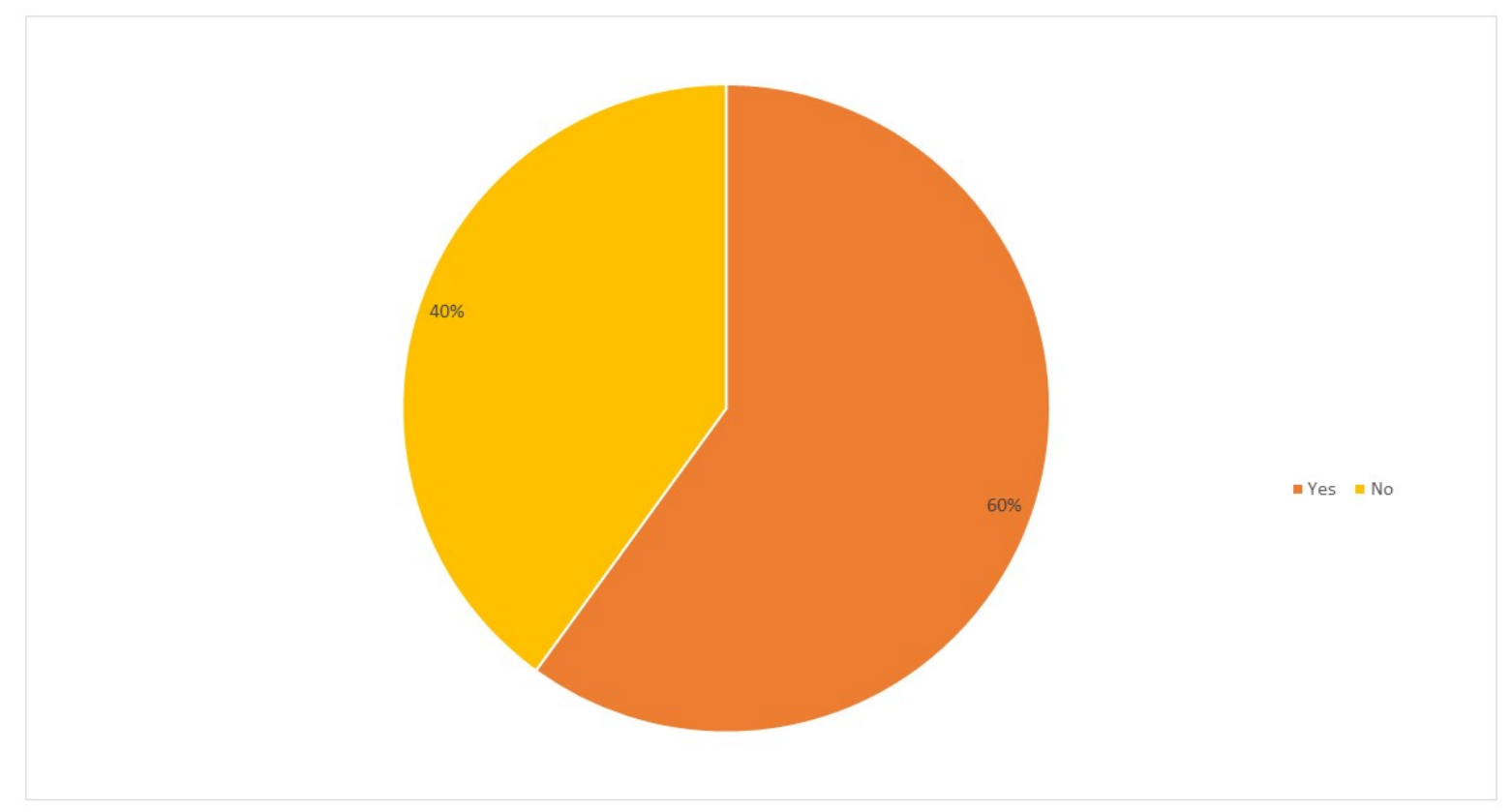

Chart 7. Whether cultural beliefs limiting postnatal mothers' movements influenced utilization of postnatal care services.

Table 5. Distance to Nakasongola Health Center IV from respondents' home

\begin{tabular}{lll}
\hline Responses & Frequency & Percentage (\%) \\
Less than $1 \mathrm{~km}$ & 10 & 16.7 \\
$2-3 \mathrm{~km}$ & 20 & 33.3 \\
More than $3 \mathrm{~km}$ & 30 & 50 \\
Total & $\mathbf{6 0}$ & $\mathbf{1 0 0}$ \\
\hline
\end{tabular}




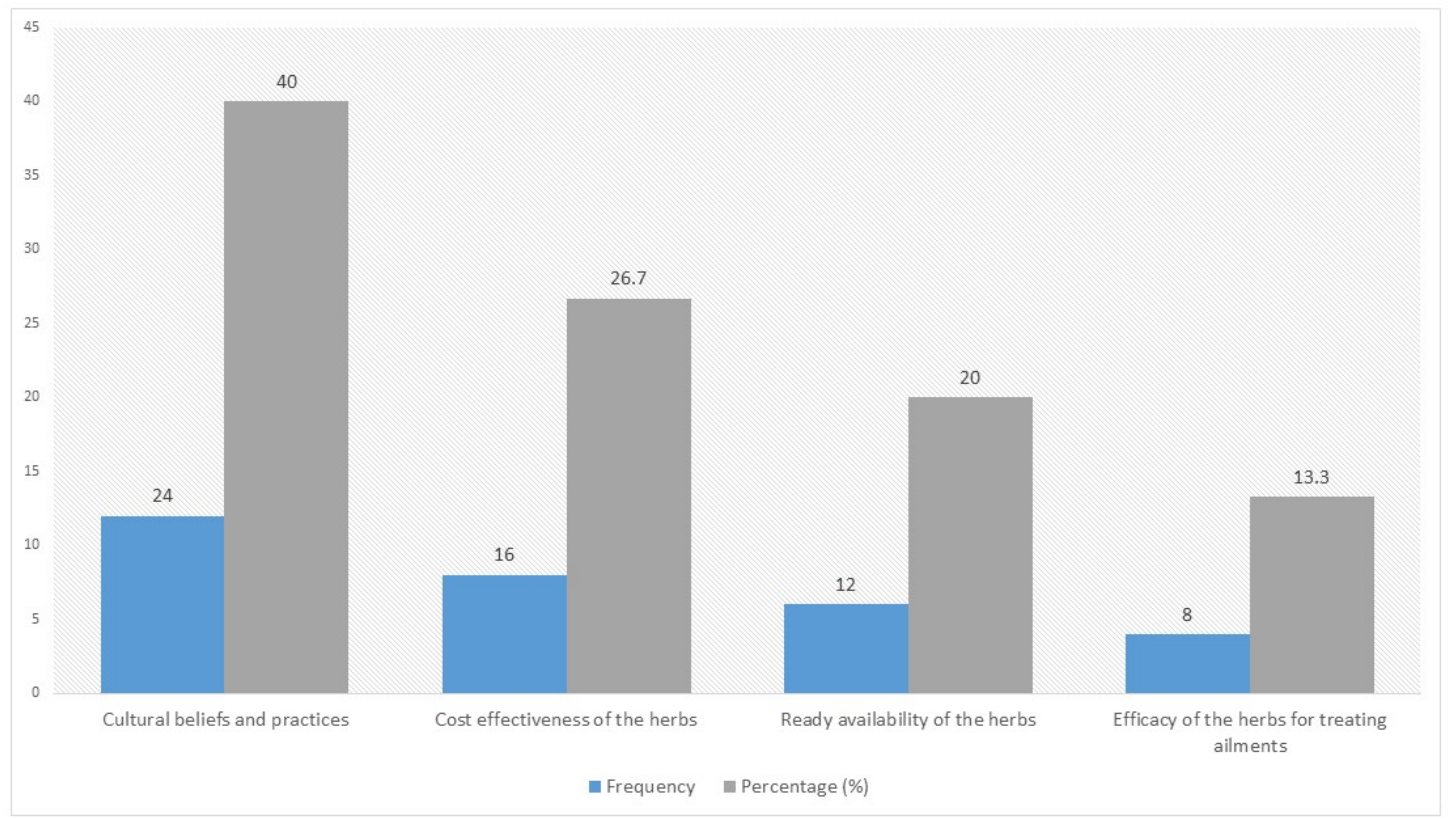

Chart 8. Reasons why women used herbs to treat ailments

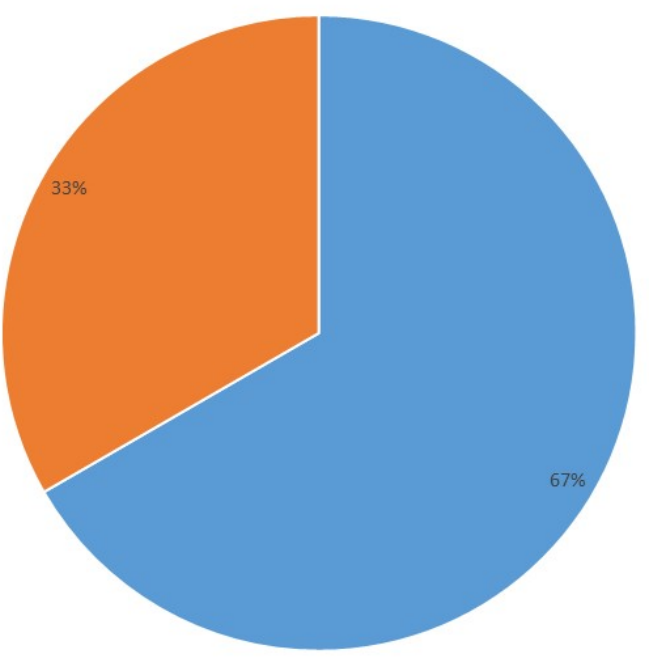

Chart 9. Distribution of respondents who used postnatal care services at Nakasongola Health Center IV 


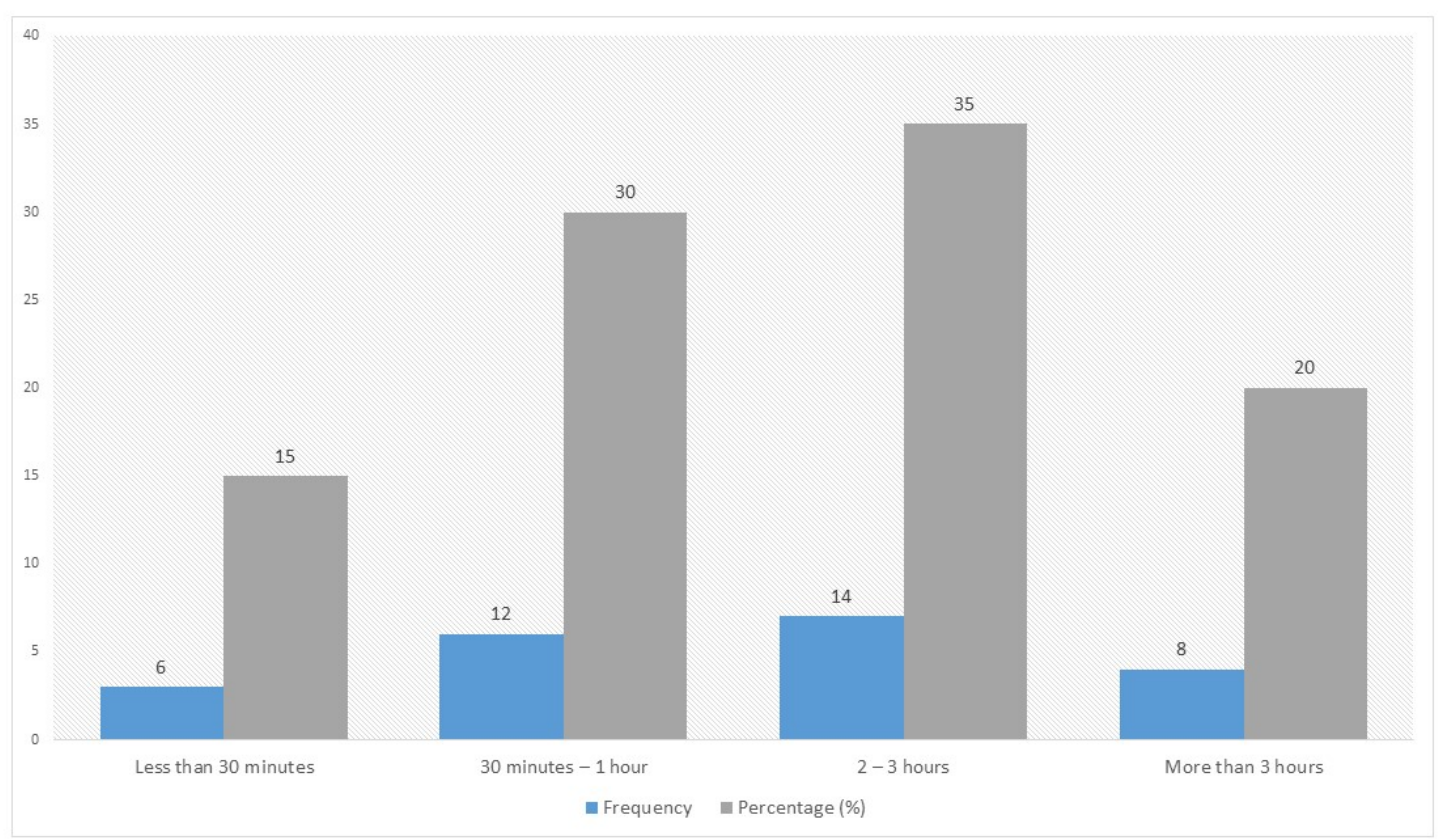

Chart 10. Waiting time to be attended to

\subsubsection{Table 6: Whether long waiting time influenced service utilization $\mathrm{n}=60$}

All 60 (100\%) respondents agreed that long waiting time influenced service utilization.

\subsubsection{Figure 12: Services provided to mothers and infants during postnatal care services $(n=60)$}

Results showed that $24(40 \%)$ respondents reported sensitization on newborn care as a service provided to mothers and infants during postnatal care, followed by 20 (33.3\%) who reported checking to ensure mother is healing properly while the least $16(26.7 \%)$ reported checking to ensure baby feeds normally.

\subsubsection{Figure 13: Whether services were provided efficiently $(n=60)$}

Results showed that 36 (60\%) respondents reported that services were not provided efficiently while the least $24(40 \%)$ reported that services were provided efficiently.

\subsubsection{Figure 14: Whether inefficient provision of services could} influence service utilization $(n=60)$ Most 50 (83\%) respondents reported that inefficient provision of services could influence service utilization while the least 10 (17\%) disagreed.
Figure 15: Whether health workers clearly explained to respondents the importance and need for post-natal care services $(n=60)$

Findings showed that $36(60 \%)$ respondents reported that health workers did not clearly explain the importance and need for postnatal services while the least 24 (40\%) reported that health workers clearly explained to them the importance and need for postnatal services.

\subsubsection{Table 7: Attitude of health workers at the postnatal clinic towards mothers $\mathrm{n}=60$}

Results showed that 24 (40\%) respondents rated the attitude of health workers at the postnatal clinic towards mothers as friendly, followed by 20 (33.3\%) who reported that they were caring while the least $16(26.7 \%)$ reported that they were rude.

Figure 16: Whether health workers approach towards mothers influenced utilization of the postnatal care services $(n=60)$

Majority 48 (80\%) of respondents agreed that health workers approach towards mothers influenced utilization of the postnatal care services while the least 12 (20\%) disagreed. 
Table 6. Whether long waiting time influenced service utilization

\begin{tabular}{lll}
\hline Responses & Frequency & Percentage (\%) \\
Yes & 60 & 100 \\
No & 0 & 0 \\
Total & 60 & 100 \\
\hline
\end{tabular}

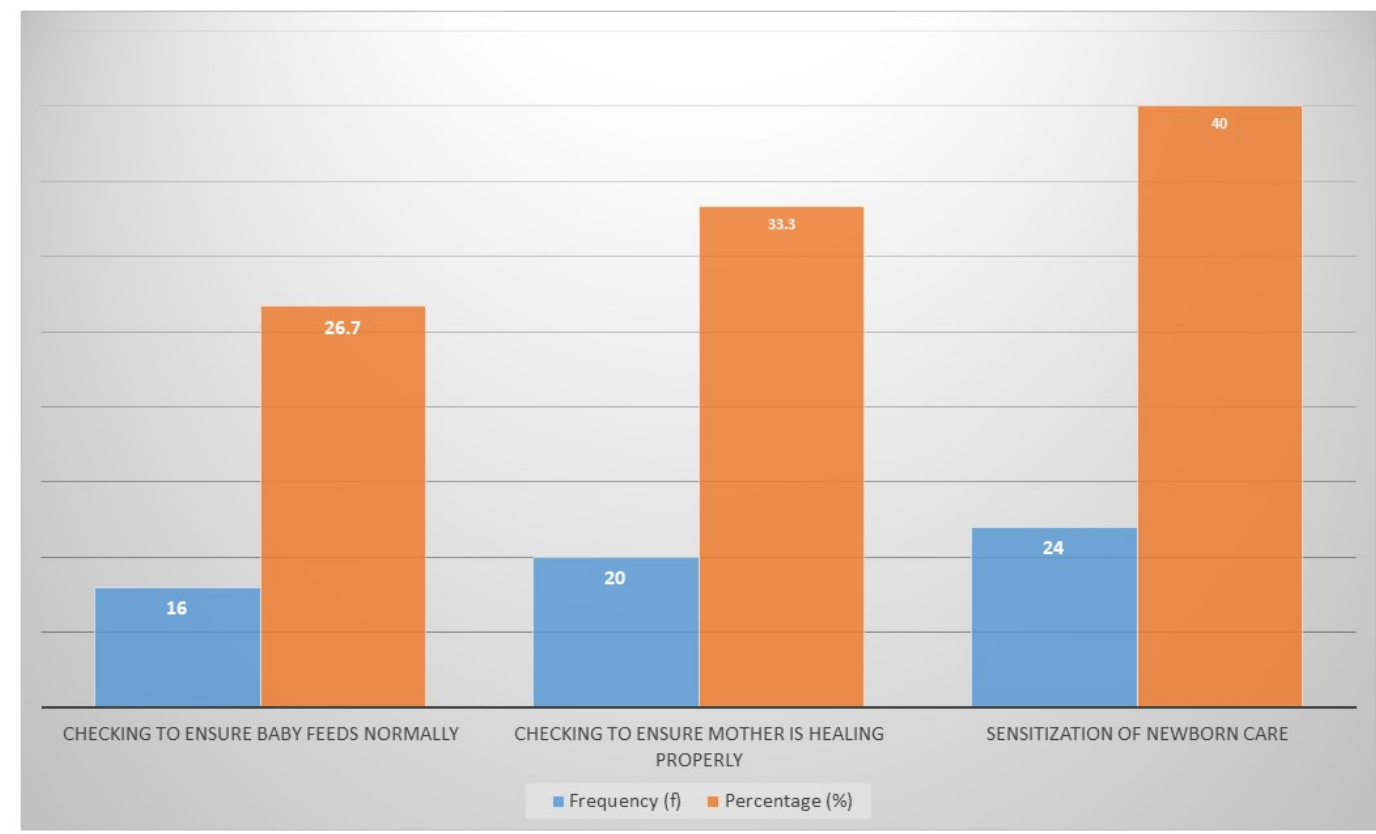

Chart 11. Services provided to mothers and infants during postnatal care services

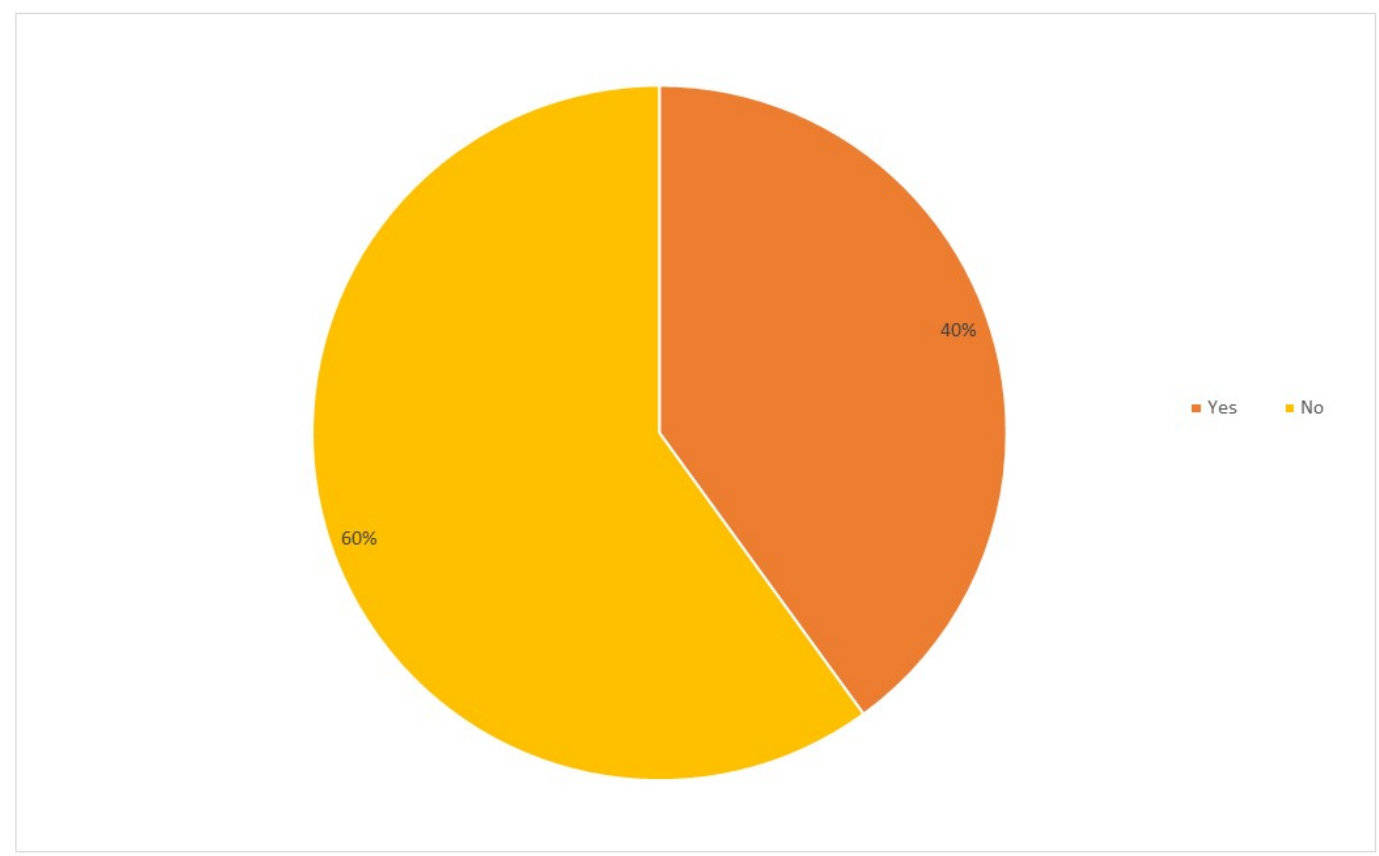

Chart 12. Whether services were provided efficiently 
Chart 13. Whether inefficient provision of services could influence service utilization

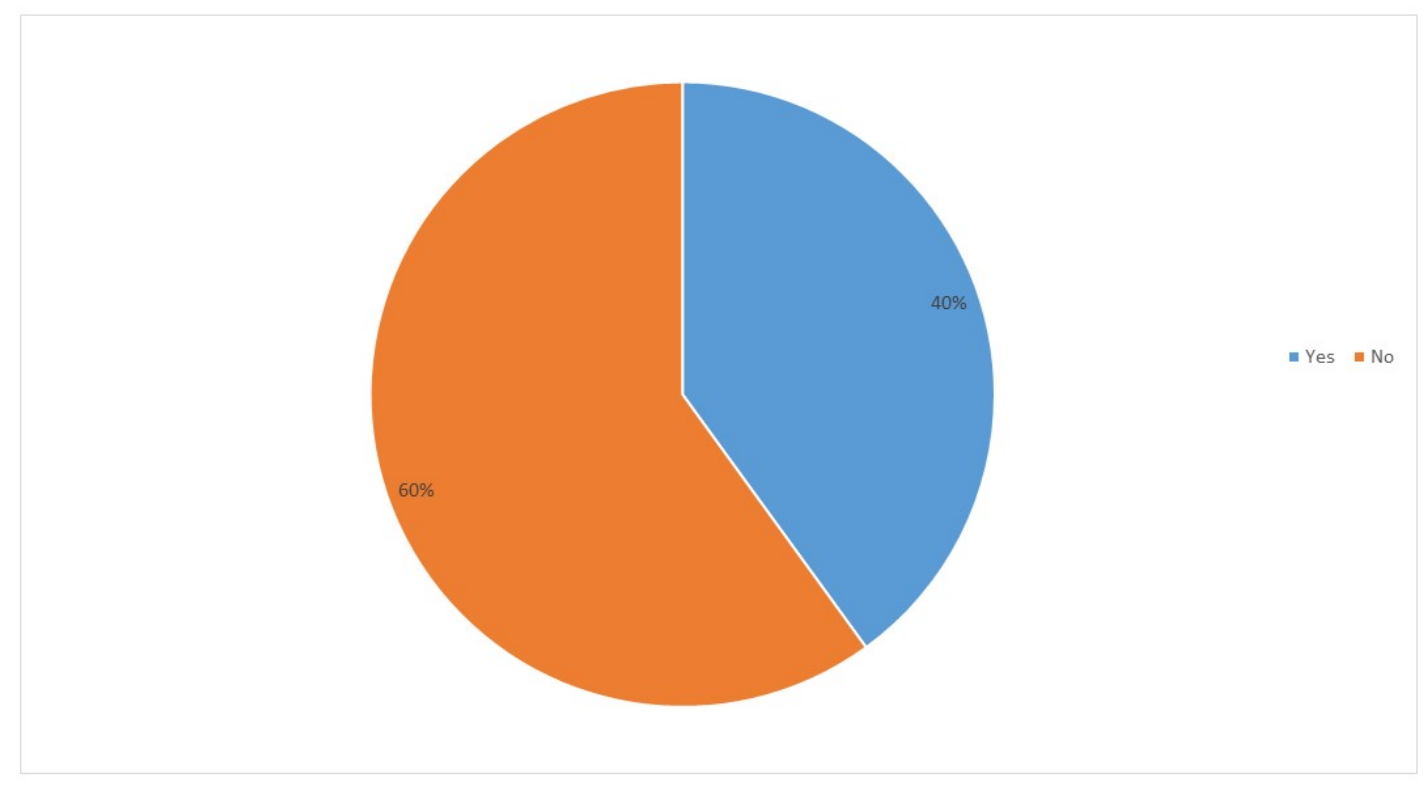

Chart 14. Whether health workersclearly explained to respondents the importance and need for post natal careservices

Table 7. Attitude of health workers at the postnatal clinic towards mothers

\begin{tabular}{lll}
\hline Responses & Frequency & Percentage (\%) \\
Friendly & 24 & 40 \\
Caring & 20 & 33.3 \\
Rude & 16 & 26.7 \\
Total & 60 & 100 \\
\hline
\end{tabular}




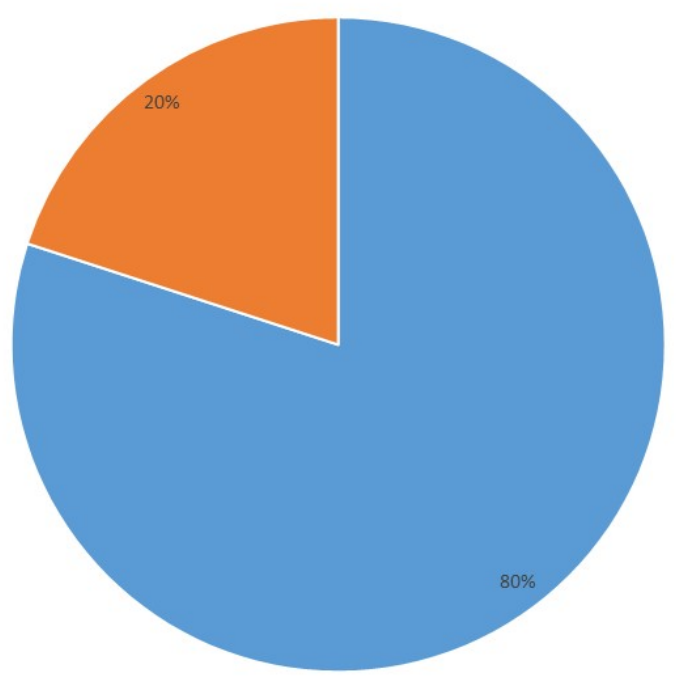

Chart 15. Whether health workers approach towards mothers influenced utilization of the postnatal care services

\subsubsection{Table 8: Whether health workers were readily available for postnatal care services}

\section{$7 \mathrm{n}=60$}

Half $30(50 \%)$ of the respondents reported that health workers were sometimes readily available for postnatal services, followed by 20 (33.3\%) who reported that they were always readily available while the least $10(16.7 \%)$ reported that health workers were never readily available.

\section{1}

\subsubsection{Table 9: Other health facility related factors influence utilization of postnatal care service among mothers $\mathrm{n}=60$}

Results showed that $24(40 \%)$ reported long waiting time to receive services as a health facility determinant of postnatal care services utilization among mothers services among mothers, followed by 16 (26.7\%) who reported negative attitude of health workers, $12(20 \%)$ reported lack of sensitization about the importance of postnatal services while the least $8(13.3 \%)$ reported under staffing.

\section{Discussion, Conclusions and Recommendations Demographic and Social Characteristics}

Results showed that 24 (40\%) respondents were in the age range of $26-35$ years, which implied that respondents were mature enough to understand and appreciate the importance and need for utilizing postnatal care services. This study finding was similar to Ronsmans et al., (2012) which revealed that the age of the mother has been reported as a major socioeconomic determinant of postnatal care services utilization among mothers services. It was further reported that adolescent or younger mothers were less likely to access and make adequate use of skilled delivery services in time as compared to older mothers.

Results showed that 24 (40\%) respondents never went to school, followed by 16 (26.7\%) who attained primary level education. This implied that since most respondents attained a low level of education, they may not be aware or even appreciate the importance of postnatal services. This study finding was in line with a study by Onah et al., (2014) in Enugu, Nigeria which revealed that some of the socio-economicdeterminants of postnatal care services utilization among mothers includedlevel of education of themother, the long distances to health units, economic status of women and the remote- 
Table 8. Whether health workers were readily available for postnatal care services

\begin{tabular}{lll}
\hline Responses & Frequency & Percentage (\%) \\
Sometimes & 30 & 50 \\
Always & 20 & 33.3 \\
Never & 10 & 16.7 \\
Total & $\mathbf{6 0}$ & $\mathbf{1 0 0}$ \\
\hline
\end{tabular}

Table 9. Other health facility related factors influence utilization of postnatal care service among mothers

\begin{tabular}{lll}
\hline Health facility factors & Frequency & Percentage (\%) \\
Long waiting time to receive services & 24 & 40 \\
Negative attitude of health workers & 16 & 26.7 \\
Lack of sensitization about the importance of postnatal services & 12 & 20 \\
Understaffing & 8 & 13.3 \\
Total & $\mathbf{6 0}$ & $\mathbf{1 0 0}$ \\
\hline
\end{tabular}

ness of their residence as well as lack of reliable and affordable transport.

Findings showed that $36(60 \%)$ respondents were peasant/farmers, followed by 14 (23\%) who were self-employed which was in line with Campbell et al., (2014) whose study about the strategies for reducing maternal mortality: getting on with whatworks revealed that some of the social-economic determinants of postnatal care services utilization among mothers include marital status and occupation of the women. It was noted that employed women and housewives are more likely to timely access and utilize postnatal care services than women who are not married.

Results showed that 38 (63.3\%) respondents were married, which implied that since respondents were married, they would count on and receive financial, emotional, and physical support from their husbands to access and utilize postnatal care services which were in line with Campbell et al., (2014) whose study about the strategies for reducing maternal mortality: getting on with what works revealed that some of the social-economic determinants of postnatal care services utilization among mothers include marital status and occupation of the women. It was noted that employed women and housewives are more likely to timely access and utilize postnatal care services than women who are not married.

Half 30 (50\%) of the respondents had 2 - 3 children, followed by 20 (33.3\%) respondents who had 5 children and above. This implied that since most respondents had more than 1 child, they would have more experience and hence better able to ensure utilization of postnatal care services.

\section{Socioeconomic determinants of postnatal care services utilization among mothers}

Findings showed that 24 (40\%) respondents had a monthly household income of 50,000 100,000 shs, followed by 16 (26.7\%) who had a monthly household income of 100,000 200,000 shs. This demonstrated that respondents had a low level of income and hence poverty could influence their ability to access and utilize postnatal care services. This study finding was in line with Van Eijk et al., (2014) who noted that in rural western Kenya, socio-economic determinants of postnatal care services utilization among mothers includedthe high levels of poverty, unemployment as well as lack of support from partners. It was further noted that the majority of respondents only went in for skilled delivery services as a last resort and did not see any need to spend much money on transport and health care services when they could deliver at home alone, unassisted, or with other attendants and extended family members such as grandmothers and mothers.

Half 30 (50\%) of the respondents reported that they sometimes received support from their husbands to access postnatal care while 16 (26.7\%) respondents mentioned lack of awareness as a socio-economic determinant of postnatal care services utilization among mothers which implied that failure to receive consistent support from their part- 
ners could greatly influence utilization of postnatal services. This study finding was supported by Van Eijk et al., (2014) who noted that in rural western Kenya, socio-economic determinants of postnatal care services utilization among mothers included lack of support from partners.

Results showed that 14 (23.3\%) reported poverty, $12(20 \%)$ reported unemployment which implied that financial factors were some of the prevalent issues influencing postnatal service utilization. This study finding was similar to Kiwanuka et al., (2013) whose study about access to and utilization of health services for the poor in Uganda document that socio-economic determinants of postnatal care services utilization among mothers by rural women are the status of the family, whereby those who were impoverished were unlikely to access and make use of the available maternal health services.

A total of $8(13.3 \%)$ respondents reported a lack of funds for transport, 6 (10\%) reported lack of funds for health services while the least 4 (6.7\%) reported lack of support. This study finding was in line with Kiwanuka et al., (2013) whose study about access to and utilization of health services for the poor in Uganda document that socio-economic determinants of postnatal care services utilization among mothers by rural women are the status of the family, whereby those who were impoverished were unlikely to access and make use of the available maternal health services.

Cultural determinants of postnatal care services utilization among mothers

Results showed that most 40 (67\%) respondents reported that cultural beliefs did not allow postnatal mothers to freely move and access health care services. This study finding was in agreement with Kyomuhendo et al., (2013) who revealed that some of the cultural determinants of postnatal care services utilization among mothers included a predominance of patriarchal societies where all decisions were made by the men were revealed to be some of the cultural determinants of postnatal care services utilization among mothers by rural women.

Out of the 40 respondents who reported that cultural beliefs did not allow postnatal mothers to freely move and access health care services, most 24 (60\%) reported that these cultural beliefs limited mothers' utilization of postnatal services. This study finding was in line with Kagaayi et al., (2014) whose study about maternal self-medication and provision of nevirapine to newborns by women in Rakai, Uganda revealed that in Uganda,cultural determinants of postnatal care services utilization among mothers included women's status, preference for traditional care, cultural beliefs and limited resources that the decision on time and place of delivery depends primarily on family (especially the husband's) preferences and that if the husband preferred TBAs, then TBAs were used for delivery. Furthermore, it was revealed those women's inability to independently make labor and delivery decisions also influenced the utilization of postnatal care services.

All 60 (100\%) respondents reported using herbs to treat the ailment in the postnatal period while 24 $(40 \%)$ respondents reported that they used herbs to treat ailments because of cultural beliefs and practices. This study finding was in line with Itina et al., (2014) whose study among the Offot Clan, Nigeria revealed that important cultural determinants of postnatal care services utilization among mothers included prevalent cultural beliefs and practices which praised unassisted deliveries and honor women who went through such deliveries and never sought any services were some of the cultural determinants of postnatal care services utilization among mothers by rural women.

Results showed that 16 (26.7\%) respondents reported cost-effectiveness of the herbs, 12 (20\%) ready availability of the herbs while the least 8 (13.3\%) reported efficacy of the herbs for treating ailments. This demonstrated that most respondents used herbs for various reasons which greatly influenced attendance of postnatal services as these herbs were deemed effective for treating ailments. This study finding was in line with Nikiema et al., (2014) whose study about providing information on pregnancy complications during antenatal visits: unmet educational needs in subSaharan Africa carried out in several sub-Saharan African countries including Nigeria and Ivory Coastnoted that an important cultural factor contributing to late reporting for delivery is the promotion of self-delivery as well as treating women who delivered unassisted had also been noted as one of the major determinants of postnatal care services utilization among mothers, especially by rural women.

Health facility determinants of postnatal care services utilization among mothers

Half 30 (50\%) of the respondents resided $2-3 \mathrm{~km}$ away from Nakasongola Health Center IV, followed 
by 20 (33.3\%) who resided $2-3 \mathrm{~km}$ away which demonstrated that most respondents resided a long distance to the health facility. However, longdistance to health facilities could greatly influence the utilization of postnatal care services. This study finding was in line with Kiwanuka et al., (2013) whose study mentioned that a major health facility determinant of postnatal care services utilization among mothers services included long distance to service points, perceived quality of care, and availability of services and health workers.

Results showed that 40 (67\%) respondents had ever used post-natal services at Nakasongola Health Center IV, 14 (35\%) reported waiting for 2 - 3 hours before receiving services yet all 60 (100\%) respondents agreed that long waiting time influenced service utilization. This demonstrated that the long waiting time to receive services greatly influenced the utilization of postnatal care services. This study finding was in line with Asuquo et al., (2012) whose study about staff attitude as a barrier to the utilization of University of Calabar Teaching Hospital for Obstetric care among pregnant women, findings revealed that long waiting time to receive services, failure of providers to convey information about the importance of postnatal care services for all women were health facility determinants of postnatal care services utilization among mothers by rural women. Others included negative attitudes and poor customer care towards mothers.

Results showed that 24 (40\%) respondents reported sensitization on newborn care as a service provided to mothers and infants during postnatal care, followed by 20 (33.3\%) who reported checking to ensure the mother is healing properly while the least 16 (26.7\%) reported checking to ensure baby feeds normally. This implied that since respondents were aware of the various services provided to them and the newborns could positively influence their utilization of postnatal care services. This study finding was in line with Sugarman et al., (2011) whose study in Ghana revealed that some of the health facility determinants of postnatal care services utilization among mothers were lack of sensitization about the importance of timely access to and utilization of delivery services. It was noted that mothers did not adequately report and utilize postnatal care services in time and this was attributed to a lack of clear sensitization and education campaigns about the benefits of timely access to these services such as prevention of maternal morbidity and morbidity.

Results showed that $36(60 \%)$ respondents reported that services were not provided efficiently yet most 50 (83\%) respondents reported that inefficient provision of services could influence service utilization which was in line with Kiwanuka et al., (2013) who mentioned in their study that a major health facility factor influencing utilization of postnatal care services included long distance to service points, perceived poor quality of care and unavailability of services and health workers.

Findings showed that $36(60 \%)$ respondents reported that health workers did not clearly explain the importance and need for postnatal services which implied that failure to clearly explain the importance of postnatal services could greatly influence utilization of the postnatal care services. This study finding was in line with Sugarman et al., (2011) whose study in Ghana revealed that some of the health facility factors influencing utilization of postnatal care services included lack of sensitization about the importance of timely access to and utilization of these services. It was noted that mothers did not adequately utilize these services due to inadequate health education about their importance.

Results showed that 24 (40\%) respondents rated the attitude of health workers at the postnatal clinic towards mothers as friendly which was in line with Asuquo et al., (2012) who reported in their study about staff attitude as a barrier to the utilization of University of Calabar Teaching Hospital for Obstetric care among women revealed that long waiting time to receive services, as well as negative attitudes of health workers towards the mothers, led to low uptake of the services.

The majority $48(80 \%)$ of respondents agreed that health workers' approach towards mothers influenced utilization of the postnatal care services which implied that health workers' attitude towards patients could greatly influence utilization of postnatal care services. This study finding was in line with Mwaniki et al., (2009) whose study about the utilization of antenatal and maternity services by mothers seeking child welfare services in Mbeere District, Eastern Province, Kenya revealed that some of the health facility determinants of postnatal care services utilization among mothers included by rural women included perceived lack of skilled staff in public facilities as well as the use of 
unwanted delivery positions and a poor approach to mothers by health staffs.

Half 30 (50\%) of the respondents reported that health workers were sometimes readily available for postnatal services. This implied that the unavailability of health workers greatly influenced the utilization of postnatal care services. This study finding was in line with Kiwanuka et al., (2013) who mentioned in their study that a major health facility factor influencing utilization of postnatal care services included long distance to service points, perceived poor quality of care, and unavailability of services and health workers.

Results showed that 24 (40\%) reported long waiting time to receive services as a health facility determinant of postnatal care services utilization among mothers services among mothers. This study finding was in agreement with Asuquo et al., (2012) who reported in their study about staff attitude as a barrier to the utilization of University of Calabar Teaching Hospital for Obstetric care among women revealed that long waiting time to receive services, as well as negative attitudes of health workers towards the mothers, led to low uptake of the services.

A total of 16 (26.7\%) respondents reported negative attitudes of health workers as health facility factors influencing utilization of postnatal care services. This study finding was in line with Jokhio et al., (2010) whose study about an intervention involving traditional birth attendants and perinatal and maternal mortality in Pakistan reported that some of the health facility determinants of postnatal care services utilization among mothers were poor health worker attitudes as well as high costs of care.

Findings showed that $12(20 \%)$ respondents reported a lack of sensitization about the importance of postnatal services which was in line with Sugarman et al., (2011) whose study in Ghana revealed that some of the health facility factors influencing utilization of postnatal care services included lack of sensitization about the importance of timely access to and utilization of these services. It was noted that mothers did not adequately utilize these services due to inadequate health education about their importance.

\section{Conclusion}

The study results revealed that respondents faced various socio-economic determinants of postnatal care services utilization including lack of awareness, poverty, unemployment, lack of funds for transport and health services, and lack of support.

The study also revealed that respondents faced various cultural determinants of postnatal care services utilization including cultural beliefs which did not allow them to freely move and access health care services, using herbs to treat the ailment in the postnatal period.

Furthermore, the study also revealed various health facility determinants of postnatal care services utilization including long distance to the facility, long waiting time to receive services, inefficiency in service provision, and failure of health workers to clearly explain the importance and need for postnatal services.

\section{Recommendations}

The Ministry of Health should strengthen the available national sensitization programs aimed at sensitizing mothers about the importance and need for postnatal services.

The Ministry of Health should reenergize efforts to ensure that all mothers receive adequate sensitization about the availability of postnatal services and the importance of using these services.

Health workers at Nakasongola Health Center IV should endeavor to always health educate mothers about the importance of using postnatal care services as well as the dangers of not fully utilizing these services.

There is also a need for health workers to invite the participation and involvement of male partners to improve the support provided to these mothers.

Postnatal mothers at Nakasongola Health Center IV should endeavor to make adequate use of postnatal services for their benefit and their infants as well.

Mothers should encourage the participation and involvement of their husbands to improve service utilization.

There is also a need for efforts to call for addressing some cultural practices which in one way or another limit service attendance and utilization.

\section{Nursing Implications}

Health workers at Nakasongola Health Center IV have an important role to play in improving the utilization of postnatal services. This could be 
achieved through health educating mothers about the importance and benefits of using these services as well as the dangers to the mother and infant of not using these services.

\section{Acknowledgment}

I thank the Almighty Father for taking me through this 3-year course, for the good health, support, provision, and journey mercies.

Great thanks go to the team at Nakasongola District Local Government, especially Dr. Agaba Byamukama and Dr. Mutebi Thaddeus, for the opportunity given to complete my course, the office of the Chief Administrative Officer for all their support.

Great thanks go to the administration of Nakasongola Health Center IV for allowing me to carry out this research at the health center, the staff for their cooperation during data collection as well as all my respondents who accepted to participate in the study.

I wish to thank the administration of Uganda Martyrs University-Nsambya Campus, especially the coordinator, all the teaching and non-teaching staff for availing us a conducive atmosphere to study.

Lastly, to my classmates, for all the support and encouragement throughout the course.

May God reward you all abundantly.

\section{Definition of Terms}

Post Natal Services These are special services offered to mothers and infants immediately following the birth of a baby up to 6 weeks.

Skilled Delivery Services is defined as the provision of delivery and maternity services by individuals professionally trained to handle childbirth and labor such as midwives and obstetricians/gynecologists.

Late Reporting This is where mothers delay in accessing skilled delivery services even after witnessing signs for the onset of labor.

Challenge These are tests, trials, and issues that may affect the use of a particular service.

Socio-economic factors These are issues attributed to how economic activity affects and is shaped by social processes such as unemployment, poverty, level of education, etc.

Health facility factors These are issues attributed to the accessibility and utilization of health care services such as customer care skills of health staff, availability of services, etc.
Cultural factors These are issues attributed to an individual's tribe and its beliefs, customs, and norms, etc.

Safe motherhood is defined as a means of ensuring that all women receive the care they need to be safe and healthy through pregnancy and childbirth.

Factors These are predisposing issues, conditions that make it very hard for an individual to utilize something.

Risk Factors These are signs, conditions leading to serious conditions

\section{Abbreviations}

AIDS: Acquired Immune Deficiency Syndrome

ANC : Antenatal Care

DISH: Delivery of Improved Services for Health

EMTCT : Elimination of Mother to Child Transmission of HIV

HIV : Human Immunodeficiency Virus

HMIS : Health Management Information System

MOH : Ministry of Health

SDG : Sustainable Development Goal

TBAs : Traditional Birth Attendants

UDHS : Uganda Demographic and Health Survey

UNESCO : United Nations Education, Scientific and Cultural Organization

UNICEF : United Nations Children's Fund

VCT : Voluntary Counseling and Testing

WCBA : Women of Child-Bearing Age

WHO : World Health Organization

\section{A References:}

1) Achola, R., Ramadhan, H., \& Opio, C. (2013). Involvement of traditional birth attendants for the prevention of mother-to-child HIV transmission in Tororo district, Uganda. Paper presented at: PEPFAR Implementers Meeting; June 16-19, 2007; Kigali, Rwanda. Abstract 1123.

2) Adamu, Y.M., \& Salihu, H.M. (2013). Barriers to the use of antenatal and obstetric care services in rural Kano, Nigeria. J Obstet Gynaecol.22:600-603. https://doi.org/10.1080/0144361021000020349

3) Asuquo, E.E.J., Etuk, S.J., \& Duke, F. (2012). Staff attitude as barrier to the utilization of University of Calabar Teaching Hospital for Obstetric care. African Journal of Reproductive Health, 4(2):69-73. https://doi.org/10.2307/3583450

4) Itina, S.M. (2014). Characteristics of traditional birth attendants and their beliefs and prac- 
tices in the Offot Clan, Nigeria. Bull World Health Organ.75:563-567.

5) Jokhio, A.H., Winter, H.R., \& Cheng, K.K. (2010). An intervention involving traditional birth attendants and perinatal and maternal mortality in Pakistan. N EngI J Med.352:2091- 2099. https://doi.org/ 10.1056/NEJMsa042830

6) Kagaayi, J., Dreyfuss, M., \& Kigozi, G. (2014). Maternal self-medication and provision of nevirapine to newborns by women in Rakai, Uganda. J Acquir Immune Defic Syndr.;39:121-124. https://do i.org/10.1097/01.qai.0000148530.66587.7c

7) Kasenga, F., Hurtig, A.K., \& Emmelin, M.H. (2013).Home deliveries: implications for adherence to nevirapine in a PMTCT programme in rural Malawi. AIDS Care.19:646- 652. https://doi.org/10. 1080/09540120701235651

8) Keusch, G.T., Wilentz, J., \& Kleinman, A. (2011). Stigma and global health: a research agenda. Lancet, 367(9509):525-527. https://doi.org/10.10 16/S0140-6736(06)68183-X

9) Kiwanuka, Ekirapaa \& Peterson (2013). Access to and utilization of health services for the poor in Uganda: a systematic review of available evidence. Trans R Soc Trop Med Hyg. 102(11):1067-74 https:// doi.org/10.1016/j.trstmh.2008.04.023

10) Kyomuhendo, G.B. (2013). Low use of maternity services in Uganda: impact on women's status, traditional beliefs and limited resources. Reprod Health matters, 11(21):16-26. https://doi.org/10.10 16/S0968-8080(03)02176-1

11) Mwaniki, K., Kabiru, D., \& Mbugua, T. (2009) Utilization of antenatal and maternity services by mothers seeking child welfare services in Mbeere District, Eastern Province, Kenya. East Afr Med J.79:184-187. https://doi.org/10.4314/eamj.v79i4. 8875

12) Nikiema, B., Beninguisse, G., \& Haggerty, J.L. (2014). Providing information on pregnancy complications during antenatal visits: unmet educational needs in sub-Saharan Africa. Health Policy Planning, 24:367-376. https://doi.org/10.1093/heapol/c zp017

13) Onah, H.E., Ikeako, L.C., \& Iloabachie, G.C. (2014). Factors associated with the use of maternity services in Enugu, southeastern Nigeria. Soc Sci Med, 63:1870-1878. https://doi.org/10.1016/j.socsc imed.2006.04.019

14) Ronsmans, C. \& Graham, W.J. (2012). Maternal mortality: who, when, where, and why. The
Lancent. Volume 368, No. 9542, p1189-1200. https: //doi.org/10.1016/S0140-6736(06)69380-X

15) Sugarman K. (2011). Roadmap for Accelerating the Reduction of Maternal and Neonatal Mortality and Morbidity. Lancent. Volume 368, No. 9542, p89-120.

16) Van Eijk, A.M., Hanneke, M., Bles, J., Odhiambo, F., John, G., Ayisi, L., Ilse, E., Blokland, H., Daniel, H.R., Kubaje, A., Slutsker, L., \& Lindblade, K.A. (2014). Use of antenatal services and delivery care among women in rural western Kenya: a community based survey. Reprod Health; 3: 2. 45-56. h ttps://doi.org/10.1186/1742-4755-3-2

17) WHO (2013). Recommendations on Postnatal care of the mother and new born Trop Med Int Health, 11(2):238-51. http://apps.who.int/iris/bitstr eam/handle/10665/97603/9789241506649_eng.p df?sequence $=1$

18) WHO (2018). State of health care services delivery. WHO Publication, Geneva, Switzerland. 